\title{
A CONCISE GUIDE TO THE ASSESSMENT OF THE GERIATRIC PATIENT AND THE APPROACH TO TREATMENT
}

A Paper delivered by Miss A. J. Savin, M.C.S.P., S.A.S.P., during the session on Geriatrics of the 4th Congress of the World Confederation for Physical Therapy, on the morning of 21 st June, 1963. In conjunction with it is a printed" chart, "A Concise Guide to the Assessment of the Geriatric Patient and the Approach to Treatment, designed to answer the question "Where is
your Patient on the road to Independence?"

A copy of the printed chart was issued to members on entering the auditorium, at the beginning of the session.

The care of the aged, as an organised effort on a nationwide basis, is comparatively new in South Africa. Much has been done to create public interest in the past six years, by the formation of the National Council for the Welfare of the Aged, to which the South African Society of Physiotherapy and many of the local institutions are now affiliated.

The South African Society of Physiotherapy is deeply concerned that Physiotherapy should be available, through the developing Medical and Welfare Services, to all persons in South Africa handicapped by the disabilities of old age.

Many organisations, both state-aided and private, offer services to the elderly and aged, some in hospitals, some in Old People's Homes, and others in the aged person's own home. For example, the Department of Social Welfare and Pensions, subsidises 78 Old People's Homes throughout South Africa, and the beautiful seaside resort of Durban can boast of over 20 private old people's homes in its vicinity.

Old People's Homes are available for all racial groups in this multi-racial country; the African Bantu, the Coloured, the Indian, the Asiatic and the European. There is a higher proportion of organised old people's homes for the European population than for the African. Due to their particular social structure, the elderly Bantu are more likely to be cared for back in the kraal, in the family circle by children and grandchildren. This family care is sadly lacking in some of our modern communities which consider that old people are not the responsibility of the family, but of the State.

Many of the Old People's Homes in South Africa being new have the advantage of the latest ideas in construction and equipment. Of course, buildings are not everything; the success of the home depends far more on the spirit inside, and on whether the people in it are happy. When I went to see the Afrikaans Home in Pretoria, the residents showed me round and I was passed on from friend to friend. They were proud of the building, which obviously was convenient, but the residents very strongly made the point that they had found friendship and companionship and were never lonely. I knew then why the home was called "Ons Tuis"-Our Home.

The South African Society of Physiotherapy, feels, that now that the ancillary services are being established in many of the new Old People's Homes, it would be regrettable if, with such excellent living conditions, the elderly people in them lacked adequate Physiotherapy and rehabilitation
on the spot.

The Vice-Chairman of the South African Society of Physiotherapy, Mr. Alfred Rothberg, of the Southern Transvaal Branch, has been our pioneer in this field. He implemented a pilot scheme under which a number of Physiotherapists have, on a voluntary basis, visited several OId People's Homes in Johannesburg, once a week to give treatment. From this small beginning the Witwatersrand Jewish Aged Home now has a well-developed Physiotherapy Department with paid staff, and the Bramley Old People's Home has just appointed a part-time paid Physiotherapist. Other branches of the South African Society of Physiotherapy have followed the idea, and members have offered practical help in their own districts.
The Society aims at co-operation with other bodies, it also encourages the co-operation of its individual members with other medical workers. This is of particular importance in the approach to treatment of the Geriatric Patient, where a common aim more easily produces satisfactory results.

\section{The Assessment Chart:}

The importance of co-operation is reflected in the text of the printed chart, which you received at the beginning of the session. This chart can be used in practice to assess the position of the individual patient as suggested by the heading "Where is your patient on the road to Independence?" though it may be of more value in indicating the attitude necessary in the Physiotherpist and her co-workers to obtain an all-round assessment and approach to treatment.

The need for a chart was possibly more evident some years ago, but one still finds occasions when the ideas need re-statement, for example, in the chronic ward where the patient still remains in bed, or in the acute ward of a general hospital where, even though the patient is permitted to sit out of bed, the tempo of work in the ward, high beds and slippery floor militate against the rehabilitation of any less agile person.

On the chart you will find the factors favourable to the patient's recovery set out on top. By contrast, those factors unfavourable to recovery, will be found in the columns below. The factors, chosen as being of most interest to the Physiotherapist, are divided into five sections:

1. Physical factors;

2. Mental and Economic factors;

3. Bed Rest factors;

4. Mobility factors; and finally

5. Treatment and Time factors.

\section{Section 1:}

The first section indicates the need to review the state of all the body systems, because one would expect that, after so many years of life, some of them would be wearing out: It also shows some of the conditions commonly treated by the Physiotherapist.

\section{Section 2:}

The second section shows the contributory factors which may have to be overcome. It is interesting, and surprising, to see how these two sets of factors sometimes balance each other out in the final state of the patient's mobility. For example, one patient with numerous physical disabilities, failing sight, a weakening heart and stiffening joints may manage to keep going and will recover with treatment, because of her grit, courage, and will power; while another, far less disabled, will fail, having apparently neither the will to recover, nor anything to live for.

\section{Section 3:}

In this section, the adverse effects of prolonged Bed Rest; Bed sores; Contractures; Incontinence, and Mental Apathy are stressed pictorially. 
I have often seen an apparently senile, incontinent patient nursed in a cot bed, who recovers dramatically when lifted out of bed into a comfortable chair that gives her safe support and brings her into a more upright position.

\section{Section 4:}

Section 4 shows the need for equipment which will help the progression into the upright as soon as possible, from bed to chair, and from standing to walking.

The basic equipment should be re-assessed and, if necessary, redesigned, to suit the size and needs of the individual patient.

While allowing for nursing care and for support of the painful joints, the bed and chair must give the mechanical aid and the feeling of security which will encourage the patient to move automatically and to change her position.

The elderly patient must feel safe when carrying out a movement, especially if it is a new manoeuvre, and advantage should be taken of mechanical aids and helpers to effect a progression. In order to give the patient assurance that it is safe to move and then confidence in her ability, it is better to overdo help at first, than to have insufficient help. The elderly patient will discourage excessive help once she is capable of doing without it, as long as she knows that it is available if necessary.

When the patient is in bed, forward placed handles will give a better mechanical advantage for sitting forward than the usual single backward pulley over her head. A bed-chair back-rest, shaped like the top half of a chair with arms, will enable her to rock to and fro, lean forward or sideways. It can be used as a support when she sits over the side of the bed and provided her feet are supported on a foot stool or can reach the floor, she will start to turn her trunk and move her feet and knees automatically.

When she starts to get out of bed, the height of the bed is of primary importance. Although a high bed may be needed at first for nursing procedures, it should then be changed to a lower bed for rehabilitation purposes or the mattress lowered on the existing frame.

Although it is found in our modern Geriatric Units and Old People's Homes, the lower bed is often condemned in a General Hospital, as it is said to make care and bed-making a back-breaking job, but it is not realised that, if used at the right stage in recovery, it makes getting the patient into a chair or walking a far easier job for the staff and far less painful or risky for the patient.

Similarly the height of the chair seat is important when the patient is trying to stand up, balance, and sit down. Her feet must be able to reach the floor, but if the seat is too low, and her knees and hips too bent, she will not have the power to straighten them. A higher chair will be of more use for practising this, especially if the patient has a stiff hip.

In hospital, when walking is about to be started, it is often wise to bring parallel bars to the low bed side, with the bed turned broadside against the wall to make it quite stable. The patient can walk to and fro, from the bed to a rest chair or back, with the effort of getting out reduced to the minimum, and the bed is ready to hand when a longer rest is required.

It must be remembered that the elderly patient has only a certain amount of expendable energy, depending on her heart, respiration, and general health. The physiotherapist will direct her patient's energy to making useful movements. Simple repetitive movements which the patient can remember and carry out during the day are best. Small progressions should be made within the patient's known capacity, and should be suggested to her in turn.

Many an elderly patient, lying in bed, has been disheartened and has refused to move when she has been told by a well-meaning nurse or therapist that the doctor says she may now get up and walk, for she knows that even to sit up on the side of the bed or in a chair will take practice.
She must be helped by having the preliminary stages through which she will have to pass explained to her, and she need not even be faced with the final target. Then she will probably agree to start at once and to omit some of the stages.

\section{Section 5:}

The fifth and final section indicates the necessity for early treatment carried out by a team with an activity spirit and using a tempo suited to the elderly.

One might compare the potential progress of the elderly patient with the tortoise in the story of the race between the hare and the tortoise. The former races on and loses time as he stops to look about, while the latter wins the race. The elderly patient cannot expect to recover at the same rate or to the same degree as a young person, but if given time to progress slowly and steadily, she may reach her goal of independence in a bed, or in a chair or walking far sooner than expected.

\section{THE APPROACH TO TREATMENT}

Assessment by means of the chart leads to the "Approach $\boldsymbol{C}$ to Treatment" as shown beneath each section and which is $\backslash$ summarised as follows:

Strive for the best approach to treatment:

1. Find the Precipitating Cause.

2. Look for the Contributory Causes.

3. Avoid prolonged dependence in bed.

4. Progress to the upright as soon as possible, using equipment, favourable to movement.

5. Give early treatment remembering the slower tempo of the elderly.

\section{Epidiascope:}

This is the Witwatersrand Jewish Aged Home in Johannesburg, to which I have referred.

Slide $1-$ Here is a picture of Mr. Rothberg who started the Geriatric Physiotherapy there, with his band of voluntary helpers.

Slide 2-Here is the voluntary work in progress at the Bramley Home.

Slide 3-This shows some of the patients playing skittles in the gymnasium. The frames in the background are designed to slide over the beds for suspending apparatus.

Slide 4-This is the Afrikaans Old People's Home in Pretoria "Ons Tuis".

Slide 5-Mrs. J. Mundt, one of the residents with some of her friends, who showed me around. Mrs. Mundt is of Hugenot and German decent. She talked to me of South Africa history.

Slide 6-This was Mrs. Mundt's original home which was built by the Voortrekkers, and which she presented to the country as a National Monument when she came to "Ons Tuis".

Slide 7-This shows Mrs. Hall, aged 95 of Nelspruit, Eastern Transvaal. She and her husband were from Great Britain and were the first settlers to live and survive in the lowveld, then a malarial area. They built up what is now one of the largest Citrus Estates in South Africa. Her account of her life and experiences are described in her book No Time to Die, which she wrote at the age of 90 , a copy of which you can also see on our stand.

Slide 8-This is a home for sick and aged Bantu in Vendaland, Northern Transvaal, run by a Mission Church. The residents themselves have named it Khathutshelo"Place of Compassion". 